\title{
American doctors urge medical evaluations for all concussed athletes
}

A

n influential doctors' group wants Americans to take the risk of sports concussions more seriously and is recommending that organizers of sports programs for children, teens and adults take stronger action to limit potential harm to athletes.

A new position statement from the American Academy of Neurology recommends that any athlete who is suspected of having suffered a concussion be removed from participation until evaluated by a physician trained in the management of sports concussions (www .aan.com/globals/axon/assets/7913.pdf).

The academy is also recommending that no athlete be allowed to participate in sports while still experiencing concussion symptoms and that any athlete who suffers a concussion consult a neurologist or physician with proper training before returning to play.

Another recommendation from the academy is sure to prove more difficult to implement: The neurologists recommend that a certified athletic trainer be present at all sporting events - including practices - where athletes are at risk for concussions.

Even Dr. Jeff Kutcher, lead author of the academy's position statement and chair of its sports neurology section, acknowledges that's not always feasible, due to the costs and limited availability of certified trainers. But he says the recommendation makes a statement about "what we think our priorities should be."

"If a school does not have access to a certified athletic trainer, they need to think long and hard about the safety of their kids and whether they should have contact sports," he says.

Kutcher says the most significant point in the neurologists' position statement may be its shift away from a past practice parameter document that established a return-to-play protocol based on a graded scale of symptoms. The new emphasis on treating athletes

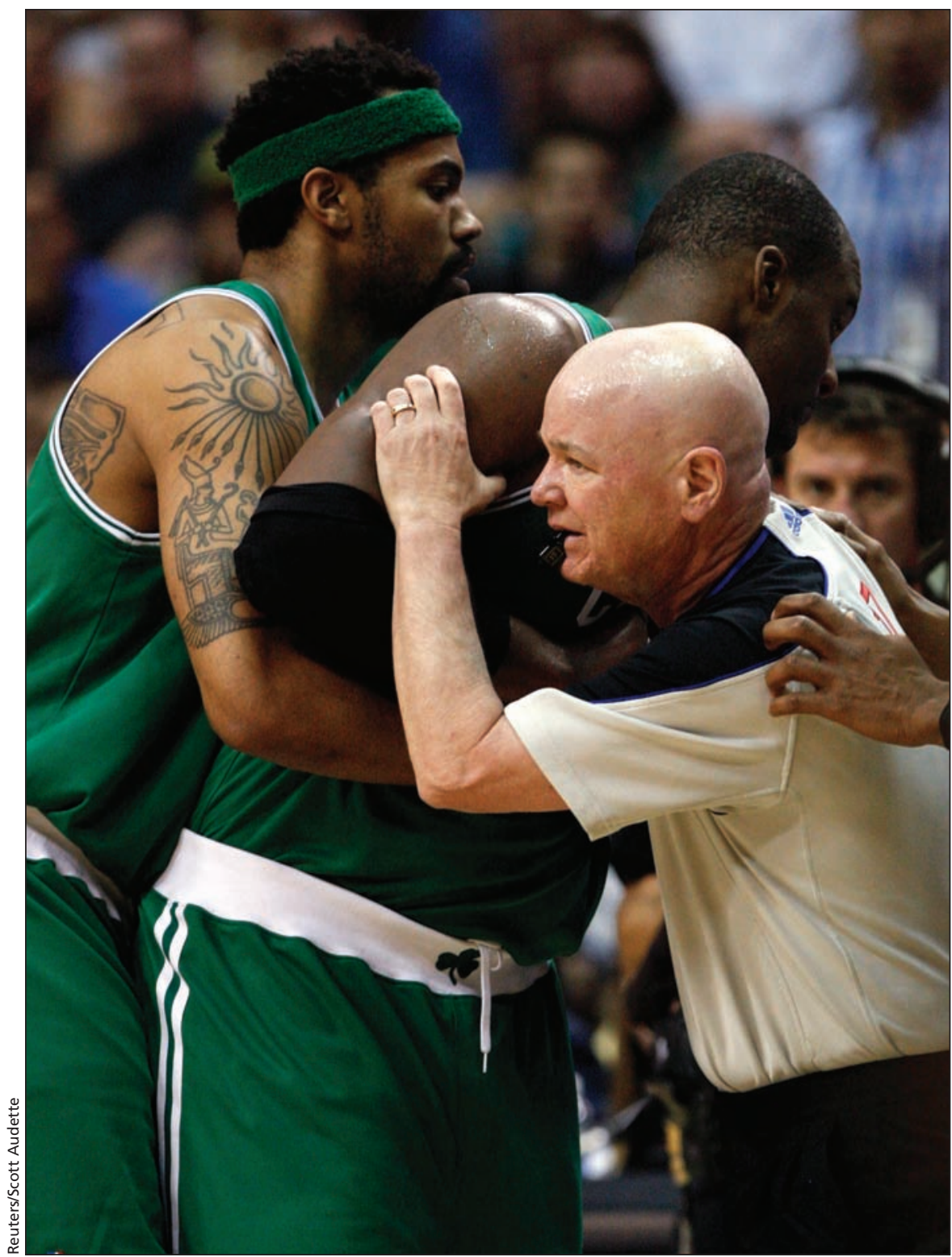

Boston Celtics power forward Glen Davis is held up by an official and teammate Rasheed Wallace after being hit with an elbow and receiving a concussion during last spring's National Basketball Association playoffs.

as individuals, he says, should result in more athletes "going back to play when it is safe to do so and not too early and not too late."

The National Athletic Trainers' Association says only about $40 \%$ of United States high schools have access to certified trainers for student athletes.
Tamara McLeod, an associate professor in the athletic training program at A.T. Still University in Mesa, Arizona, says that in cases when a certified athletic trainer isn't available, better education of parents and coaches about the importance of not returning athletes to play too soon is critical. In 
addition, she says, communities need to establish networks of medical professionals who are qualified to assess and manage concussions.

McLeod, who is studying quality-oflife issues in concussion victims, also says more attention needs to be paid to ensuring that young people who are recovering from concussions get the help they need both socially and academically, not just in returning to the playing field. She says there is often a "disconnect" between school athletic and academic programs, and young athletes with concussions can have trouble keeping up with homework and other issues.

It's been estimated that as many as 3.8 million sports- and recreationrelated concussions occur in the US each year ( $J$ Head Trauma Rehabil 2006; 21:375-78). And the US Centers for Disease Control and Prevention (CDC) says children and teens are more likely to get a concussion and take longer to recover than adults.

Young athletes are at greater risk than college or professional athletes because their brains are more susceptible to injury, according to the athletic trainers' association, which also says that female athletes are more vulnerable to concussions than males.
Yet Kutcher says the gap in proper management of concussions "essentially gets bigger the younger we're talking about."

The CDC has cautioned that even a mild "ding" can be serious. And it says a repeat concussion that occurs before the brain recovers from the first can increase the potential for long-term problems. A CDC fact sheet for coaches warns that "in rare cases, repeat concussions can result in brain swelling, permanent brain damage and even death" (www.cdc.gov/concussion/pdf/coaches _Engl.pdf).

The new position statement from the neurologists' group comes at a time when there is growing focus in the US on the potentially devastating effects of sports concussions.

The CDC, working in partnership with the National Football League, has created a new poster to educate young athletes about concussions, and is urging every school and sports league in the country to hang it in locker rooms and gymnasiums (www.cdc.gov/concussion /pdf/poster_Eng.pdf).

In the fall of 2010, the Democraticcontrolled US House of Representatives approved legislation that would set federal guidelines for managing concussions among student athletes, including standards for when athletes can return to play. But the bill was not expected to win final approval from the existing Congress, and prospects are uncertain for legislative action in the next session, when control of the House will shift to Republicans.

A number of states have enacted concussion laws of their own, and sporting organizations have taken voluntary steps to deal with concussions more seriously.

The National Football League has adopted rules to keep players with concussions off the field and is cracking down on illegal hits to prevent concussions in the first place.

The National College Athletic Association adopted a policy requiring schools to have concussion management plans, and to have athletes with symptoms of a concussion evaluated by a healthcare provider with experience in managing sports concussions.

The National Hockey League has banned blindside hits to the head, and Major League Baseball is considering setting up a seven-day stay on the disabled list for players with concussions. - Nancy Benac, Washington, DC

CMAJ 2011.DOI:10.1503/cmaj.109-3739 